\title{
EDITORIAL
}

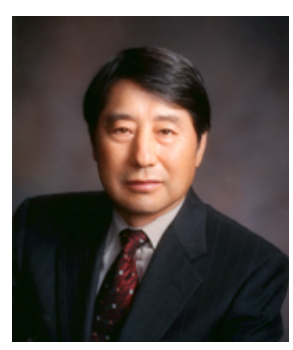

\section{Congratulation Remark for the New Journal Biomedical Engineering Letters}

\author{
Sung Wan Kim
}

(C) The Korean Society of Medical \& Biological Engineering and Springer 2011

I am writing this comment as a congratulation remark for the new journal, Biomedical Engineering Letters, which is an official journal of the Korean Society of Medical and Biological Engineering.

The area of biomedical engineering started in the late 1960 's and early 1970's. As the interdisciplinary approach continues to grow, this area has been very active. Biomaterials, biomechanics, bioelectronics diagnostic and imaging, tissue engineering and drug delivery have been included in this active research and development area. The combined discipline has resulted in the creation of better artificial organs. The artificial organ research has created many medical device products.

Dr. W.J. Kolff invented the artificial kidney in 1943. He successfully implanted a complete artificial heart in a human in 1983. Numerous other medical devices are produced based on combination of biomaterials and electronics technologies.

This research will be continuously active due to the current major market it is fulfilling. Tissue and cell engineering are an important area since this approach is only possible when combining technologies or disciplines, as the pharmaceutical approach is not feasible to do it alone.

Stem cells and many other cells are investigated and several clinical evaluations are currently underway. Diagnostic and imaging is another exciting new area since new products and equipment can be developed in shorter time periods.

Bioengineers can move into gene therapy research. Gene delivery especially siRNA delivery will be the ultimate method to treat disease patients. Delivery research can be formulated by collaborating with gene biologists.

Korea had a duplication period in the early 1970's with their research and development. It moved into a modification period in the 1970's and 1980's. Now it is the time to engage in innovative research. Biomedical engineering has a strong capacity to achieve this objective.

I congratulate the inauguration of Biomedical Engineering Letter journal and believe it will be successful. 